\title{
MEDICINA MÀGICA A LES COMARQUES DE LA MARINA. PAPERS MASCULINS I FEMENINS
}

\author{
REGINA RAMÓN SAPENA \\ ISABEL BETLLOCH MAS \\ EUSEBI CHINER VIVES \\ Universitat Miguel Hernandez (Elx)
}

La medicina popular consisteix en l'estudi de les tradicions ancestrals i costums de tipus religiós popular que el poble ha emprat per guarir i previndre tot tipus de malalties. La malaltia és un fenomen inseparable de la vida i totes les societats han fet front als problemes que aquesta planteja. Al món actual existeix un elevadíssim nombre de sistemes mèdics que han persistit al llarg del temps i que podem tipificar partint dels fonaments en què es basen: creences màgico-religioses, l'empirisme i la ciència. Els dos primers apareixen associats amb distinta proporció i sovint, sobretot als països desenvolupats, coincideixen o conviuen amb el sistema mèdic tradicional, amb um equilibri més o menys inestable. La medicina popular està present en les colectivitats urbanes i inclou tota una sèrie de normes de conducta, valors i criteris, idees i visió de les coses, vocabulari, etc, relacionades amb la salut, les malalties i la lluita contra aquestes.

L'empirisme mèdic comprén principalment el món de l'etnofarmacologia, sobre les que conflueixen la botànica, l'etnologia i la història. La medicina popular basada en les plantes medicinals és molt ampla i rica a l'àrea mediterrània $i$ excedeix de les intencions del present treball.

Pel contrari, el curanderisme es troba a cavall entre l'empirisme i el sistema mèdic tradicional comportant-se el curander com un pràctic de la medicina popular que empra elements d'ambdos sistemes. Els rituals i pràctiques integren aspectes culturals i socials i també les motivacions dels seus participants. El curanderisme i la pràctica màgica constitueixen un sistema d'acció social basat en el rol i l'estatus, el qual s'adquireix baix distintes formes.

Als països mediterranis i concretament al País Valencià, la dona ha jugat un paper clau en el manteniment i pervivència d'aquestes pràctiques. A més a més del seu tradicional rol a la família en quant a cura de la casa i els fills, ha ocupat el seu paper en el coneixement dels remeis per a conservar la salut i ha estat dipositària de coneixements ancestrals. Aquests sovint són cassolans, per ús o 
administració «domèstica» als propis integrants de l'unitat familiar. En altres casos s'obre més enllà del nucli íntim, per a trascendir a la comunitat complint aquest rol o status a què ens referiem. Sorgeixen així les figures de les quals parlarem a continuació com la medidora i que podriem considerar «especialistes» en matèries concretes, quasi sempre marcades per la «gràcia» o capacitat, heretada, rebuda, adquirida o transmesa conformat un sistema estructurat. Les creences religioses sense dubte impregnen aquestes pràctiques, però algunes d'elles són de marcat caràcter pagà o han estat paganes en el seu origen.

La dòna, però, comparteix aquest status amb l'home, el qual adopta més sovint, però no de forma exclusiva, els papers específics que requereixen força, habilitat manual, o què per les seues característiques podrien no estar socialment ben considerades per a una dona, tal és el cas de l'eixarmador, del componedor o del saludador.

En el present treball comentem alguns aspectes relacionats amb la medicina màgico-religiosa què hem pogut comprovar encara són vius al nostre entorn. Per raons pràctiques, l'àmbit del treball es va restringir a les comarques de la Marina Baixa i Marina Alta (Alacant) i no preten ser exhaustiu, ja que més bé representa una xicoteta mostra del nostre patrimoni. Hem exclòs els aspectes relacionats amb la etnobotànica i el vocabulari mèdic popular i que han estat objecte d'altres treballs dels autors ${ }^{1}$. El treball ha estat basat en informants, entrevistes sistemàtiques i en els repertoris bibliogràfics a l'abast.

\section{REMEIS MÀGICS}

Hi ha malalties considerades pel poble no mèdiques i per al seu tractament s'utilitzen oracions acompanyades de maniobres no perjudicials, perquè la medicina popular estricta no tracta de curanderisme, i les persones que diuen aquestes oracions no solen actuar de forma comercial, simplement coneixen la oració transmessa per un familiar o amic; aquesta transmissió es fa normalment en Dijous o Divendres Sant o en determinades condicions. Les persones encarregades de dir les oracions solen ser majoritariament dones, devotes de la Santisima Trinitat i la Verge.

\subsection{Trencar els golls}

En relació al tractament de les adenopaties agudes, ganglis que solen eixir als costats del coll, braç o cama durant les infeccions, hi ha un ritual anomenat trencar els golls que consisteix en trencar, o millor dit aplastar eixos ganglis, palpant aquests nóduls amb el dit polze untat en oli o saliva i deslliçant-lo cap amunt i cap abaix, per la cara interna del braç, coll o cama, buscant els bultets o bo-

1. Chiner, E.; Andreu, A.; PAStor, E. et. al.: «El lèxic pneumològic a les Comarques de la Marina i l'Alacantín, Xé Congrés de la Societat Valenciana de Pneumologia, Alacant, 2003 (Premi de la Societat Valenciana de Pneumología a la millor comunicació oral). RAMÓN, Regina: L'expressió dermatologica al llenguatge popular valencià. Amb especial referencia a la comarca de la Marina Baixa, Tesi doctoral. Departament Medicina Clinica, Universitat Miguel Hernandez. Alacant, juny 2006. 
nyets i amb el fregament s'aplasten fins que es desfan. Aixó pot acompanyar-se d'oracions a la Santísima Trinitat. Aquest ritual pot ser practicat per qualsevol persona, inclús el propi malalt, encara que no tinga gràcia i és una pràctica amplament extesa als pobles de la Marina Baixa. A tots els pobles solia haver una persona exterta en aquesta tasca ${ }^{2}$.

\subsection{Llevar o traure el sol del cap}

El sol al cap o insolació té un primer símptoma clar que és quan la suor del cap s'asseca sola, s'evapora quan ix, sense necessitat d'utilitzar el mocador o passar la mà. Si no es busca una ombra i es continua al sol, es nota certa fluixesa, puja la febra, en ocasions té vertigen i sempre excitació nerviosa.

Es tracta popularment amb un ritual específic i molt conegut anomenat llevar el sol del cap, que consisteix en treure l'excés de calor del cos amb aigua freda, acabada de pouar de l'aljub, omplint un got d'aigua o amb una botella de vinagre i colocant-lo damunt del cap, fins que s'escalfa amb el calor que ix del cos i que, a voltes, es manifesta amb un sangrat pel nas, pot ser indicant l'eixida del calor.

El resultat és miraculós i són molt poques les voltes que la operació resulta fallida ${ }^{3}$.

\subsection{Trencar l'enfit}

L'enfitament, entripament o empatx (també anomenat tenir una parà) és una indigestió del ventrell i el podem agafar per moltes i variades causes, sempre al voltant de la menjada, per massa menjar, inoportunament o amb fàstic. La fruita verda pot ser l'origen de la major part d'ells.

Trencar l'enfit és un remei popular per a aliviar o curar l'estat d'enfitament.

És administrat per dones que tenen gràcia -la medidora o trencadora- $i$ han aprés les oracions el Dijous Sant a les dotze de la nit davant del Monument del Senyor, transmeses per una altra dona de poder semblant i que en general ja és molt vella per a exercir o vol traspassar-les a una filla o a una dona d'alguna població que no dispose de trencadora d'enfit.

Quan una persona està enfitada, la trencadora té dues modalitats per a tornar la pantxa al bon camí.

Una es possar-se dret davant la mestressa, que agafa un mocador de seda (en alguns pobles ha de ser roig i para tota la nit de Dijous Sant) sota el llit d'un Crist ajegut gran (la llargaria ha de ser tres vegades la distancia entre el colze i

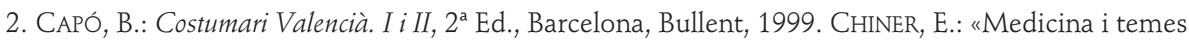
relacionats», en P. Almiñana: Diccionari temàtic de Benidorm, Regidoria de Cultura. Ajuntament de Benidorm (en premsa). MARTínez I MARTínez F.: Coses de la meua terra. La Marina, Altea, Aitana, facsímil, 1987. MARTínez I MARTínez F.: Coses típiques de la Marina, la meua comarca, València, L'Estel, 1970..

3. Fresouet, J.L.; Tronchoni, J.A.; Ferrer, F.: Salut, malaltia i terapèutica popular, València, Ajuntament de Catarroja, 1994. GIl BARBERÁ, J. i MARTí MORA, E.: Medicina valenciana mágica y popular, València, Carena, 1997. 
la punta del dit gros de la mà) i li'l dóna al malalt el qual l'agafa entre els dits polze i l'índex posant-se'l a la panxa i d'ací a la panxa de la trencadora. Des de la panxa seua a la del malalt mesura tres colzades (aplica el colze del braç dret a la punta del mocador) i amb la mà estirada subjecta amb les puntes dels dits índex i del cor tot el que pot alcançar, l'agafa amb la mà esquerra i el passa pel colze tres vegades. Aleshores, solta les tres parts i el pacient, igual que abans, es posa al ventre una punta de la mida exacta i l'altra punta a la panxa de la trencadora. Ho tornen a mesurar i si resulta la mida exacta a la que han feta abans, el malalt ja està bo; si en la tercera colzada, la veta es queda curta, a l'altura del ventre o del pit, allí on apleguen les puntes dels dits, és fins allí que li aplega l'enfit4.

Mentre va medint va fent la senyal de la Santa Creu i resant mentalment una oració. Les oracions poden ser alguna d'aquestes:

«Per la mà de Jesús i Maria

I després la meua

Amb la túnica del nostre Senyor i el mant de Maria

Jesús corona i claus

Possa les teues mans Senyor i jo possaré les meues

Amb la túnica del Senyor i el mant de Maria

Jesús possa les vostres mans

Jo possaré les meues

Jesus corona i claus»

El malalt diu:

"Al principi del temps

Sant Gregori es va empatxar

I en el nom del seu fill

La Verge s'el va curar»

El sanator diu:

"Amb la meua mà pecadora,

Que Deu, el pare, va crear,

A tu l'empatx de dues boles,

He de curarte jo.

Pare, Fill i Espíritu Sant

Que baixe la pelota

I tú satanàs no l'evitaràs

Perque amb mí està

La Santisima Trinitat»

L'altre sistema emprat és el de preparar un platet amb una mica de oli en què la dona mulla els dits i deprés va fregant, mentres resa, al voltant del melic del malalt. Amb un parell de sessions el bony del ventrell va minant fins que desapareix del tot i deixa la panxa llesta per noves aventures gastronòmiques.

4. CAPÓ, B.: Op. cit., MARTínez I MARTínez, F.: Coses de la meua terra..., op. cit. MARTínez I MARTíNEZ F.: Coses típiques de la Marina..., op. cit. 
Les dones no poden cobrar però s'agraeix la seua administració del remei amb productes casolans com ara ous, coques, una gallina o un conillet.

Els xiquets sovint jugaven a enganyar la trencadora, la qual, només veure'ls, ja sabia que no estaven enfitats i els despatxava.

\subsection{Posar les canyes}

Posar les canyes és un procediment per a tractar el dolor lumbar, que consisteix en colocar dues canyes a l'alçada de l'àrea lumbar, que agafa per un costat el malalt i per l'altra el componedor, qui al temps recita una oració. Si les canyes es creuen, el mal es va resolent, mentre que si es mantenen en la posició inicial el diagnòstic resulta negatiu i també la seua acció terapeútica ${ }^{5}$.

\subsection{Nit de San Joan}

És la nit del 23 al 24 de Juny i es considera una nit màgica en la que es fan rituals per a obtenir remeis populars però també és el moment en que les persones (homes i dones) dotades de gràcia poden transmetre els seus coneximents als seus succesors.

Alguns exemples de tractaments obtinguts eixa nit consisteixen en posar aigua a la llum de la lluna per a després utilitzar-la en massatges o friccions per a tractar la caiguda del cabell. També al ficar-se a la mar al tocar les dotze d'eixa nit hi ha la creença de que es curen les malalties especialment les de la pell. Revolcar-se sobre herbes eixa nit diuen que cura la llepra ${ }^{6}$.

\subsection{Vestit de frare}

A Altea on hi ha un convent de frares franciscans, hi havia, i encara hi ha una gran devoció al pare Sant Francesc i predilecció pel seus religiosos, de manera que encara avui solen anomenar flares als sacerdots. Hi ha una tradició antiga que diu que quan algun xiquet estava malalt i deshauciat pels doctors, i els curanders declaraven l'impossibilitat de la cura acudien al Sant d'Asís fent-li la promesa de que si el xiquet curava el vestirien de frare. Quan el bon pare s'apiadava de la pena dels devots pares de la criatura o a la natura li donava la gana de fer un impossible, encomanaven un habitet a mida i el xiquet quedava convertit en un diminut frare ${ }^{7}$.

5. Balaguer, E.: «La Medicina Popular», en J.M. López Piñero (dir): Historia de la Medicina Valenciana, Tomo III, València, Vicent García editores SA, 1984, pp. 197-209. Fresouet, J.L.: Salud, enfermedad y terapeútica popular en la Ribera Alta, València, Instituto de Estudios Documentales e Históricos sobre la Ciencia. Universitat de València, 1995.

6. Gil BarberÁ, J.; Martí Mora, E.: Op.cit. Martínez i Martínez, F.: Coses de la meua terra..., op. cit. MARTíneZ I MARTíneZ, F., Coses típiques de la Marina..., op. cit.

7. MARTíneZ i MARTíneZ, F.: Coses de la meua terra..., op. cit. MARTíneZ I MARTíneZ, F.: Llegendari valencià, Alacant, Institut de Cultura Joan Gil Albert, 1996. 


\subsection{Passar la mà}

És una gràcia que tenen algunes persones, generalment dones, per a calmar els dolors o curar malalties per efecte dels massatges amb la mà, acompanyats d'oracions i d'algunes substàncies com oli o emplastres d'herbes.

\subsection{Marrubi}

És el nom que reb el Marrubium vulgare L., planta d'aspecte blanquinós per la seua abundant vellositat i olor característic, de la família de les llaviades, de fulles arrodonides i flors blanques agrupades a les aixelles de les fulles superiors, que creix a les vores dels camps, marges o escombraries. A part d'emprar-se com a fluidificant a les afeccions respiratòries i com antitèrmic en les febres pal-lùdiques, el seu ús més popular ha estat per a curar l'aliacà o icterícia.

En efecte, el malalt ha de matinar i, en dejú, deu enganyar el marrubio, la qual cosa consisteix en saludar de matí al marrubio situat a l'orinal baix del llit amb les paraules "bona nit senyor marrubio, ací li porte el pixum, la sal $i$ el senyor aliacà». Dit açó s'orina damunt la planta. Per la nit es fa el mateix romanç i cerimònia però enganyant-lo, diguent-li «bon dia». Als nou dies de repetir-ho, en la mida que el marrubi va secant-se, l'aliacà està curat.

Aquest remei no té fonament científic, però sí és cert que el període de duració de l'aliacà, quan la seua causa és de tipus infecciosa com la deguda a la hepatitis, és d'uns nou dies, desapareguent així la coloració groguenca de forma espontània. La resposta però, seria nul.la quan les causes foren d'altra naturalesa com aquelles de tipus tumoral.

Amb aquestes maniobres tenen semblança amb maniobres hindus molt antigues que traspassaven el color groc a coses grogues com el sol ${ }^{8}$.

\subsection{Prevenció de l'escaldamenta}

Portar penjat al coll un tros de card silvestre (Panical- "Eryngium campestre») és tractament preventiu de l'eczema, l'escaldamenta i les irritacions de la pell en general. A la Vila Joiosa és molt empleat aquest métode durant tot l'any pero especialment a les festes de moros i cristians que es fan a juliol, ja que fa molt de calor i a les desfilades és freqüent l'aparició de escaldadures.

\subsection{Tractament del mal d'ull}

El mal d'ull o pres d'ull es coneix desde temps remots en totes les cultures, es una malaltia produïda pel poder de la mirada d'algunes persones i que pretén perjudicar especialment a xiquets. Es manifesta per pal-lidesa, color terrós de la pell, fluixetat, aprimament, tristor i pèrdua d'apetit. És una malaltia no-mèdica i per tant no la poden curar els metges, precisa de remeis populars per a evitarla i combatre-la, com ficar un llaç roig al carret dels xiquets o dir determinades

8. Chiner, E.: Op. cit. Fresauet, J.L.; Tronchoni, J.A.; Ferrer, F.: Op. cit. 
oracions. Abans de dir les oracions es santigüen, diuent el nom del xiquet i preguen, per eixemple:

«Dos (els ulls) són els que t'han fet mal.

Tres els que et tenen que curar:

Pare, Fill i Espirit Sant.

Santa Ana mare de la Verge.

La Verge mare del nostre Senyor.

Santa Isabel mare de Sant Joan Batiste.

I tota la Santisima Trinitat.

Si es una mirà la Verge Maria et té que curar.»

Una altra oració és:

"Eixos ulls que t'han mirat,

Eixa boca que t'ha parlat.

Santa Ana mare de la mare de Deu,

La mare de Deu mare del nostre senyor,

La gloriosa Santa Isabel, mare del glorios Sant Joan.

Si estes paraules son veritat

En el nom de la santisima Trinitat i la Verge Maria

Que li lleven el mal i la malaltia a (nom del malalt).»

Una variant d'aquesta darrera:

"Eixos ulls que t'han mirat,

Eixa boca que t'ha parlat.

La mare de Deu, Mare de Santa Ana,

Santa Ana mare del glorios Sant Joan.

Estes tres paraules són verges i veritat

Que li llevaran la malatia de pres d'ull a (nom del malalt)»

Després es resen tres salves repetint el nom del xiquet. L'oració es repeteix tres vegades i nou si es Dijous o Divendres Sant. S'acava fent la senyal de la Santa Creu.

\subsection{Tractament del mal aire}

Afecció coneguda desde antic per la gent gran dels nostres pobles, que sempre ens aconsellaven evitar les corrents d'aire, tapar la boca al eixir d'un lloc tancat i tapar bé la zona lumbar perque un mal aire podia donar un dolor en la «rinyonà».

Al que està afectat d'un mal aire es diu que "l'hi ha donat una bufà d'aire» $i$ ha de curar-se d'aquesta malaltia no-mèdica amb tractaments de masatges 0 herbes i sobre tot amb oracions, entre elles es troben les següents:

"Jo et conjure mal aire,

En el nom de Deu pare

Jo et conjure mal aire

En el nom de Deu fill

Jo et conjure mal aire

En el nom de l'Espírit Sant 
Les tres persones distintes i només un vertadero Deu

Monja que a l'horta estas

La nit de maitines, dia de Nadal

Hui arreplegant flors per a tractarme els mals

I per a redimir a tots els pecadors

Confia en Jesus i Santa Maria

Aquestes paraules que et dic tenen tanta virtut

Que lleven el mal i tornen la salut.»

\section{ALGUNES MALALTIES QUE ES BENEFICIEN DE REMEIS MÀGICS 2.1. Berrugues}

Les berrugues són petits tumors cutanis que ixen espontàniament per qualsevol part del cos i especialment a les mans, produint, en ocasions, una pruija molesta que ha donat peu al fet que una persona reba el nom de berrucosa quan es fa una mica pesada. Les berrugues sempre s'ha dit que desaparéixen molt per efecte de la psicoteràpia, la medicina popular o els sortilegis?.

Al voltant de les berrugues hi ha tot un món d'obscuritat del seu tractament, sempre fora de la medicina científica, deixant aquesta tasca en mans dels remeiers que mai no falten als nostres pobles.

El misteri comença amb el naiximent del remeier un Dijous o Divendres Sant i les làmines horitzontals de la part anterior del seu paladar han de tenir forma de creu. La seua gràcia li permet curar berrugues i cadascun d'ells empra el seu propi sistema de treball per a que els tumorets s'en vagen i mai més tornen

Hi ha moltíssims remeis populars per a tractar-les que van desde el clàssic remei de fer tants nusos en una corda d'espart com número de berrugues es tenen i tirar la corda dins d'un pou; quan es podreix l'espart desapareixen les berrugues. També contar el número de berrugues en silenci repetint mentalment una oració que és "Este fic es curarà per la meua gràcia i el dit de la meua mà».

Una altra manera és anar a un pou, tirar-hi dins tants cigrons secs, després d'haver-los tocat el curander, com berrugues es tinga i arrancar a córrer abans que els cigrons no toquen l'aigua. Un altre és anar a casa del remeier, que estarà en dejú, tres divendres seguits i mostrar-les les berrugues, per sobre de les quals anirà passant el dit ensalivat. El darrer i més conegut és aquell que consisteix en comptar el nombre de berrugues i escriure-lo al costat del nom en un paperet. El curander resa una oració especial i secreta que només es pot transmetre de pares a fills i només els dies més assenyalats de la Setmana Santa ${ }^{10}$.

\subsection{Padastres}

Un remei molt curiós i molt emprat per evitar els padastres, pellorfetes que apareixen al voltant de les ungles molestes i antiestètiques, és tallar-se les un-

9. Costa, I.; Roldan, G.: Enciclopedia de las supersticiones, Barcelona, Planeta, 1997.

10. SEIJO, F.: Curanderismo y medicina popular, Alicante, Biblioteca Alicantina, 1974. 
gles els dies de la setmana que no tinguen la lletra "R" (dilluns, dijous, dissabte, diumenge).

Parlant del tallament d'ungles també la creença popular diu que tallar les ungles a un xiquet baix de una figuera fa que el xiquet ixca cantador.

\subsection{Mussol}

Són tres les classes de mussols que coneixem: els ocells d'ulls grans, la perona poc animada i el furóncol que ix a al vora d'una parpella, a voltes dolorós i sempre molest. Parlem d'aquest darrer, que la veu popular sempre ha dit que era una conseqüència lògica de la formosor de la persona que els patia. Pot ser fora una manera que fer suportar millor la molesta afecció als joves que la tenien. El tractament del mussol pot fer-se de diferent maneres:

Eixir de bon matí, o a poqueta nit, a un camí de les afores i construir-hi al centre una petita piràmide de pedres mentre es recitava una cançoneta, sense la qual l'obra no aprofitava. La cançó és "a tú te'l deixe, a tú te'l done». Calia esperar que algunt vianant passés pel lloc i li donés una puntada a les pedres, pero estava prohibit tornar per a veure si el muntonet de pedra ja havia estat desbaratat. Al passar 3 o 4 dies el furóncol havia desaparegut i així augmentava la creença en l'efectivitat d'el remei.

Un altre tractament era possar una clau freda i foradada varies voltes al dia damunt del mussol

També passar la mà per l'ull tres colps dient: «mussol 4, mussol 2, mussol 3 pa tú és».

Totes aquestes són fórmules per guarir una malaltia que la naturalesa tota sola s'encarrega de dur i emportar-se.

\subsection{Herpes zòster}

L'herpes zoster és conegut com colebrina o foc de Sant Antoni i és una malaltia vírica amb dolors neuràlgics vius i erupció vesiculosa a determinada àrea de la pell. La gent pensa que és una malaltia de la sang, que s'intoxica i d'ella ix una animal que es pasetga per baix de la pell. Hi ha tractaments popular com són:

Es mata un gall i amb la sang de la pota es fan creuetes seguint el trajecte de la colebrina i aixó pot anar acompanyat d'una oració "En nom de Deu el cap i la cua et talle, Satanàs, ves-te'n a l'infern $i$ d'allà no has de torna mai mésr», la resta del pollastre es menja.

També per a "matar» la colebrina s'ha d'anar a al vora de la mar el malalt i el acompanyant. El sà agafa aigua del mar en una ampolleta dient una oració "Aquesta aigua jo recull, de la gran mar a la seua vora, per a curar a un cristià que té la colebrina». El malalt es coloca d'esquenes al mar i aguanta l'aigua, el sà mulla un pal en l'aigua i fa creus damunt la colebrina dient "Colebrina jo et mate, colebrina jo et talle, colebrina ves-te'n cap a l'infern».

Desprès de l'oració el malalt tira l'ampolla per a trencar-la i el sà tira el pal al mar. Es precís fer-lo amb aigua de mar, no serveix aigua amb sal. 


\section{SANAR PER ACTUACIÓ DE SANTS}

Tots els pobles i cultures han aprofitat la religió acudint als seus deus per a demanar salut i remei per a les seues malalties, i també han dedicat santuaris als deus sanators.

La nostra tradició cristiana també ha adjudicat el tractament de certes malaties a determinats sants segon els seus martiris o les seues vides; són els anomenats Sants sanadors.

Els Sants sanadors són un grup de 14 sants famosos per les seues curacions, així

- San Pantaleó curava l'astènia, l'aprimament i la tuberculosi,

- Sant Esteve: el mal de morros,

- Sant Donís: la sífilis,

- Sant Jordi: malalties hepàtiques,

- Sant Blai: mal de gola i estòmac,

- Sant Erasme: ventre i estòmac,

- Sant Vito: letàrgia i ball de Sant Vito,

- Sant Cristòfol: pesta,

- Sant Ciríaco: embestides del demoni, actualment epilèpsia,

- Sant Acaci: mal de cap,

- Sant Gil: bogeria,

- Sant Eustaqui: contra el foc,

- Santa Margarida: mal de ronyó i embaraç,

- Santa Bàrbara: mort repentina,

- Santa Caterina: santa consellera

Sant Antoni, encara que no inclòs dintre dels catorze Sants sanadors, té molt interés perque és invocat especialment contra les malalties de la pell. Contra la borradura de la mainada es posa oli calent de llàntia del Sant sobre la pell danyada. També és invocat sovint contra l'erisipela, i els mesells portaven una campaneta lligada al monyo amb l'imatge del Sant per a prevenir de llur proximitat a la gent ${ }^{11}$.

Altres tractaments en la línea màgica-religiosa per al tractament de la llepra consisteixen en encendre-li espelmes a Sant Llàtzer o Sant Damià o encomanarse a Job.

\section{PROFESSIONS SANITÀRIES MÀGIQUES}

Destaquem uns professionals sanitaris on la seua activitat sanadora es basava en rituals $i$ oracions màgiques. Alguns per a poder exercir aquestes pràctiques han d'estar dotats de "gràcia» i altres només fent servir els rituals ja obren efecte: componedor, medidora, saludador, saginero i eixarmador.

11. AmADES, J.: Costumari català. El curs de l'any, Barcelona, Salvat, 2003. 


\subsection{Componedor}

El componedor és un curander amb gràcia que es fa càrrec de tractar problemes deguts a causes externes de tipus traumatològic com colps, contusions, torçades, luxacions..., així com dolors d'articulacions, d'ossos, musculars i reumatològics. El procediment que més utilitzen és el massatge que s'acompanya de fregues amb alcohol o oli beneït, però també coneixien técniques de tractament de torçades. Aquest professional seria també l'encarregat del ritual de posar les canyes $^{12}$.

Encara que el componedor fa funcions de lo que avui en dia equivaldria a traumatòleg-reumatòleg, el professional a qui més s'assemblaria pels tractaments que feia servir seria al fisioterapeuta.

\subsection{Medidora o trencadora}

La medidora o trencadora és una dona que fa el trencament de l'enfit, que es un remei popular per a aliviar o curar l'estat d'enfitament. Com s'ha dit, és administrat per dones que tenen gràcia i han aprés les oracions el Dijous Sant a les dotze de la nit davant del Monument del Senyor, transmeses per una altra dona de poder semblant i que en general ja és molt vella per a exercir o vol traspassar-les a una filla o a una dona d'altra població que no disposa de trencadora d'enfit ${ }^{13}$.

\subsection{Saludador}

El saludador era la persona que tenia la capacitat o gràcia per a saludar o curar les ferides. El saludador tenia poders pràcticament des del naixement i devia reunir una o més circumstàncies: ser el setè fill d'una família de set varons, nàixer el dia de Divendres Sant o de Nadal, però sobre tot tindre una creu en el paladar, a diferència de la forma de "palmera» normal, formada pels plecs de la mucosa. Segons es deia, havien d'haver plorat tres vegades al ventre de la mare abans de nàixer. Els seus poders eren atribuïts a Santa Quitèria, verge i màrtir gallega del segle I i venerada des del segle II com protectora de la ràbia.

Els saludadors van tindre molta importància fins el segle passat, particularment fins 1885 en que Louis Pasteur demostrà la utilitat de la vacuna de la ràbia, en una època en que l'ús d'antisèptics era escàs i no existien els antibiòtics. Les primeres notícies sobre els saludadors vénen referides per frai Martin de Castañega en 1529 i en parlen d'ells molts intel-lectuals dels segles XVI al XVIII, com Benito Jerónimo Feijoo, qui va dedicar un discurs del seu "Teatro crítico Universal» (1726-1740) a aquest personatge. Els saludadors sovint van ser processats per la Inquisició, com va ser el cas de Pau Botella, pastor valencià que en 1727 va estar processat pel Sant Ofici de València i a més a més de rebre

12. Capó B.: Op. cit. Gil Barberá J. Martí Mora E.: Op. cit.

13. MARTÍNEZ I MARTíneZ, F.: Coses de la meua terra...., op. cit. 
200 assots, va estar condemnat a quatre anys de desterrament a Callosa d'En Sarrià ${ }^{14}$.

Dels saludadors de Benidorm destaquem a Antoni Calvo Llinares, Toni l'au, nascut en 1901 i mort en 1969. Tenia la creu al paladar, havia nascut en Dijous Sant i sembla que havia plorat abans de nàixer (la família no assegura aquest fet). Va exercir de saludador aplicant-se aiguardent a la boca i xuclant les ferides, curant tant mossegades d'animals com ferides infectades, alguna d'elles molt greus. Des del punt de vista científic el saludador, tret de les seues connotacions religioses, empra antisèptics (aiguardent), desbrida les ferides amb remeis físics (dents, ganivet), aplica pressió negativa (la boca) per aspirar detritus i pus, i a més a més compta amb un antibiòtic-antivíric natural en la saliva (lisozima). No dubtem per tant que la terapèutica fora en molts casos efectiva i ocupara moltes vegades el lloc del metge.

\subsection{Saginero}

El saginero deriva de la paraula sagí, mantega, greix dels animals, especialment del porc, i que es sala per a guardar-lo o es fon per a fer greix. El sagí també és una regió del baix ventre. El saginero, també anomenat enxisero, era un personatge terrorífic semblant a l'home del sac que s'enduia els xiquets. Sovint, les persones majors el nomenaven perquè els xiquets feren la migjornada o no ixqueren de casa, generalment a l'ambient del camp. Malgrat el seu aire de llegenda, sembla que respon a la figura d'un personatge real de l'Espanya del segle XIX, el qual segrestaria xiquets per treure'ls la sang i el sagí, en una època en la qual la ignorància de la medicina en el tractament de malalties com la tuberculosi i la manca d'escrúpols d'alguns, feia que persones amb diners compraren aquests remeis. La tradició conta que un xiquet de Benidorm va ser trobat amb vida a la Serra Gelada després d'haver estat segrestat i abandonat per un saginero ${ }^{15}$.

\subsection{Eixarmador}

L'eixarmador era una varietat de curandero que curava tota mena de malalties per art d'encantament, és a dir, que no tenia necessitat d'utilitzar cap tipus de medicament, perqué tirant mà dels psalms, ja foren de David o Salomó, treia les xacres dels cossos i fins i tot acabava amb aquelles que feien niu al cervell16.

Guarir per eixarm ha estat sempre una pràctica supersticiosa i no només per fer-la mitjançant les oracions secretes, sinó a més perquè s'empraven sortilegis, es miraven el pas dels estels pels camins del firmament $\mathrm{i}$, també, perque s'hi feien servir bestioles. A vegades, l'encertaven. La fama de l'eixarmador anava creixent, alhora que creixia un sentiment de respecte i d'admiració per part d'aquelles persones que havien tingut la sort de traure's de damunt la malaltia.

14. CHINER, E.: Op. cit.

15. CHINER, E.: Op. cit.

16. CAPÓ, B.: Op. cit. 
L'eixarmador era realment un especialista en tornar ossos al lloc, cosa que feia passant el dit polze per sobre de la part descojuntada mentre traçava creuetes i els llavis trenaven oracions quasi sempre tretes dels psalms. A més de resar, de tant en tant donava una bona estirada i els ossos acabaven per obeir els manejaments i tornaven al lloc primer d'on havien eixit pel qualsevol circumpstància fortuita. Encara avui tenim al nostre voltant gent aficionada que treballen per a fer un favor i no ja com a modus vivendi.

\section{CONCLUSIONS}

Als països mediterranis i concretament al País Valencià, la dona ha jugat un paper clau en el manteniment i pervivència de les pràctiques relacionades amb la medicina màgica. Ha desenvolupat el seu rol tradicional a la família, casa i fills i també ha estat part fonamental de la medicina màgica, perque ella era la poseidora dels coneixements ancestrals dels remeis per a conservar la salut.

També, a banda de tindre els coneixements, és la encarregada de dur a terme gran part de les pràctiques màgiques especialitzades per a les que cal tenir una gràcia que solament ella pot transmetre. Comparteix amb l'home altres papers específics que requereixen força, habilitat manual, o què per les seues característiques podrien no estar socialment ben considerades per a una dona.

En la revisió que hem presentat hem fem una exposició d'alguns aspectes relacionats amb la medicina popular màgico-religiosa, i hem comentat certs punts de vista d'alguns aspectes relacionats amb el paper de dones i homes en aquestes pràctiques mèdiques. 